\title{
Exploring the Emotional Experiences During Organizational Change: A Leader and Followers Perspective
}

\begin{abstract}
Muneeza Amjad ${ }^{1}$, Humera Manzoor ${ }^{2}$, Mehboob ur Rashid ${ }^{3}$
Abstract

This paper explores leader and followers' emotions in relation to the specific context of change in one of the public sector universities in Khyber Pakhtunkhwa. A qualitative approach has been used to understand the way individuals interpret situations and emotions during the change process. Data has been collected from a leader and nineteen followers through semi-structured in-depth interviews. Data was analyzed through thematic analysis to see the emergent patterns and to gain deeper insights on the way the leader and the follower interpreted situated emotions. The respondents reported mixed emotions in relation to the change process that were highly interpretive and were manifested in three main situations: when followers felt excluded from the change process; when leader encouraged followers to accept and implement change; and when followers feared repercussions of their unwillingness to accept change. This study theoretically and empirically contributes to the change management literature by demonstrating the manifestation of lived emotions during dynamic and processual change. It highlights that the lens of emotions can help to understand the micro-processes involved in the change process that is often overlooked in the change and change management literature.
\end{abstract}

Keywords: Emotions, organizational change, leader, followers.

\section{Introduction}

Public sector universities in Pakistan have undergone various structural and processual changes to improve their functioning. Most of the public sector universities in Pakistan work on traditional bureaucratic practices and processes (Parveen, Rashid, Iqbal, \& Khan, 2011). The pressure from the government through HEC (Higher Education Commission) has been mounting for universities to improve their work practices that would ultimately raise their academic standards. In this study, the

1 Research Student, Institute of Business Studies, Kohat University of Science and Technology, Pakistan.

2 Assistant Professor, Institute of Business Studies, Kohat University of Science and Technology, Pakistan.

Email: humera@kust.edu.pk

3 Assistant Professor, Institute of Management Studies, University of Peshawar, Pakistan.

\begin{tabular}{ll} 
ARTICLE HISTORY & \\
18 Oct, 2019 Submission Received & 15 Dec, 2019 First Review \\
\hline 22 Jan, 2020 Second Review & 14 Feb, 2020 Third Review \\
\hline 26 Feb, 2020 Accepted &
\end{tabular}


organizational leader of a public sector university decided to convert manual work processes to online systems by introducing computerized technology apart from introducing several other changes. The university has been reliant on manual work processes since its inception. In line with Smollan and Parry (2011), the leader indicates a person in a formal management role who either leads or implements change, such as, the Vice Chancellor of a university, whereas followers are the subordinates on whom the change is implemented. It has been already established in the current research that change involves several emotions (Smollan, 2014); however, less is known about the way they are manifested in various situational contexts emerging due to change. Consequently, the subsequent emotions depend upon the anticipation of the followers whether they will benefit from the change (Giæver, 2009; Huy, 2002).

Research on change and change management has been mainly analyzed through cognitive and behavorial dimensions whereas the emotional dimension has been largely ignored though emotions are inherent in the change process (Smollan, 2014). Traditionally, the study of emotions has been largely marginalized in the organizational context due to its negative view and because it was considered as a sign of weakness and being irrational (Fineman, 2003; Smollan, 2014). However, contemporary research shows its significance in the organizational lives of the individuals including the change process (Smollan, 2014; Kiefer, 2002; Smollan \& Sayers, 2009; Tsoukas $\&$ Chia, 2002). It has been found that individuals emotional experiences during the change process influences their commitment towards change (Huy, 2002; Kavanagh \& Ashkanasy, 2006).

A review of the literature indicates most of the researcher has either addressed the leader or a follower perspective and to study situated emotions during organizational change (e.g. Eriksson, 2004; Groves, 2006; Agote, Aramburu \& Lines, 2016; Manzoor, Johnson, \& Rashid, 2018). A significant research gap exists to incorporate both the perspectives simultaneously specifically during the during the implementation process of the change (Dasborough, Lamb, \& Suseno, 2015). This study addresses this research gap and explores the manifestation of emotions during organizational change through an interpretive approach, which is a relatively under researched area (Dasborough et al., 2015; Kiefer, 2002, 2005). Nevertheless, change can produce both positive and negative emotions as it provides opportunities and threats to individuals, but less attention has been given to positive emotions (Piderit, 2000; Smollan, 2014; Smollan \& Parry, 2011). The emphasis has been on the negative emotions as they were seen as destructive and problematic for the management that had to be controlled to have an effective change (Giæver \& Hellesø, 2010). This study incorporates both the negative and positive emotions of the leader and the follower using an interpretive approach, and contributes by arguing that emotions, irrespective of whether positive 
or negative, should be seen as a "resource" to understand the main issues at stake (Vince, 2006). Hence, this study challenges the conventional dominant rational models of change that try to control and suppress human emotions through various change management techniques (Smollan, 2014; Manzoor, Johnson, \& Rashid, 2018).

Current research shows that change is dynamic and not static or a one-time event (Tsoukas, 1998; Tsoukas \& Chia, 2002). In line with the dynamic view of change, this study takes a social constructionist view of emotions, which means they are situated in a relational context and depends upon individual's interpretations (Fineman, 2003, 2016). Unlike previous research, this study conceptualizes change and emotions as inseparable and as dynamic and processual (Dasborough et al., 2015). Hence, the purpose of this paper is to understand the way leader-follower interpretation of change defines their emotional experiences in a situated context. To understand the phenomenon in depth, this study adopts a qualitative approach. Hence, it answers the following research questions: How the leader and the followers give meaning to their emotional experiences in relation to the changes brought by the leader? What were the various aspects of the change process that were emotive for the leader and the follower? These research questions will help to gain access to the situations that are at stake during the change process since emotions help to understand the context in which they emerge.

This paper is structured as follows: It begins with the literature review that also conceptualizes change processual, dynamic, and emotive. This is followed by the context of the study. The next section discusses the methodology followed by findings. Finally, the paper ends with the discussion and conclusion.

\section{Literature Review}

Change induce several emotions due to multiple interpretation of various planned and unplanned situations (Tiedens \& Linton, 2001; Härtel \& Zerbe, 2002), which the rational model of change fails to address (Vince \& Broussine, 1996). These models view change as a problem and a deviation from management's expectations with resistance as an obvious response to change (Vince \& Broussine, 1996; Kiefer, 2002; Giæver \& Hellesø, 2010; Smollan, 2014). This infers that the rational and cognitive models of change aim to suppress human emotions and view them as irrational and an indication to an underlying problem that needs to be controlled and managed to please the management (Kiefer, 2002). Nevertheless, the rationalization of emotions during change creates further emotional dynamics that could turn out to be even more challenging for the organization to manage (Vince, 2006). Hence, this deterministic view of change overlooks the complexities, ambiguities, and subsequent emotions during the change process (Smollan, 2014). Also, emotions have been seen as a hinder- 
ance and destructive to the change process (Eriksson, 2004) which is actually a 'myth' and could turn out to be useful to the change process (Härtel \& Zerbe, 2002; Vince, 2006; Fineman, 2016). On the contrary, the reason why people resist or conform to change is significant to understand for an effective change (Kiefer, 2002; Giæver \& Hellesø, 2010). This signifies that emotions are crucial to understand in the context of change. Hence, emotions and change should be treated as inseparable as it is inherent in the change process (Dasborough et al., 2015; Helpap \& Bekmeier-Feuerhahn, 2016).

Change and change management literature particularly focuses on the behavior of the employees as a result of emotions that emerge during the change process (Saunders \& Thornhill, 2003; Avey, Wernsing, \& Luthans, 2008;) and less on the way they are interpreted in a situated context, specifically, during the change implementation process (Kiefer, 2002; Dasborough et al., 2015). Most of the research on change and change management is about resistance to change and what the management should do to overcome it (Kiefer, 2002). Thus, resistance is often seen as an undesirable behavorial outcome of negative emotions (Armenakis \& Bedeian, 1999; Piderit, 2000; Kiefer, 2005 Giæver \& Hellesø, 2010). It is assumed that change will invoke negative emotions that are seen in the form of resistance to change that overlook positive emotions. Literature suggests that positive emotions, such as, excitement, encouraging can exist along with negative emotions, such as, pain, stress and trouble (Liu \& Perrewe', 2005); hence, both should be taken into consideration.It is believed that positive emotions help individuals in managing change as it encourages them to accept and cope with the change (Avey et al., 2008), increase commitment and engagement (Staw \& Barsade, 1993), develops loyal behavior even during disruptions (Anderson \& Guerrero, 1998; Liu \& Perrewe', 2005). Also, negative emotions influence the change process (Huy, 2002; Kiefer, 2005; Maitlis \& Sonensheim, 2010) and act as a warning to address issues at stake (Elfenbein, 2007). Negative emotions signal that actions should be taken and encourage quick and full individual responses (Spoor \& Kelly, 2004). Thus, several studies on emotions during the change show the behavioral outcomes of the employees who had shown either positive or negative emotions but have seldom studied emotions in depth and as a resource to improve processes. Instead of focusing on individual emotions, several emotions, both positive and negative, can emerge during the change process that may be either complementary or contradictory that the current research lacks in its investigation (Vince, 2006; Helpap \& Bekmeier-Feuerhahn, 2016).

Traditional studies on change that remained dominant for a long time has treated change as a one-time event that is static whereas the contemporary view conceptualizes change as dynamic, emergent and an ongoing process (Tsoukas \& Chia, 2002; Klarner et al., 2011; Smollan, 2014). Secondly, studies on emotions deals with 
emotion as an event whereas change unfolds and evolves as a process that may turn out to be emergent rather than planned (Weick \& Quinn, 1999; Piderit, 2000). Also, leadership studies on emotions are occupied by the concept of emotional intelligence (Smollan \& Parry, 2011), emotion management of the leader and the followers (Glasø, Ekerholt, Barman \& Einarsen, 2006; Thiel, Connelly \& Griffith, 2012), and the use of emotions for effective leadership (Groves, 2006). Less is known about the manifestation of emotions of the leader and the follower simultaneously during the change process, which this study aims to address.

\section{Context of the study}

This research has been carried out in one of the public-sector universities of Pakistan that has a traditional bureaucratic structure. It has been conducted at the time when there was a change in leadership and a new leader brought changes to improve the processes, functions, and work practices of the university. The main change was the introduction and usage of information technology to make several processes online to enhance transparency and efficiency. This was a tedious task for the leader as several followers showed hesitance in accepting the change since they were used to manual procedures. On the contrary, some other followers were contended with the usage of information technology and showed conformity. Hence, there was a difference of opinion among the followers on how they perceived and interpreted change. Traditionally, most of the processes involved a tedious paper work that incurs massive costs to the universities, both financial and non-financial, and the motive of bringing this change was to minimize it. Also, another purpose was to keep track of various activities that would further improve the work processes in the university. Hence, it was at the time of the change being introduced when this study was conducted.

\section{Methodology}

This study takes a qualitative approach as it aims to understand the meaning people assign to their emotional experiences during the change process. The ontological view of this study is a relativist one, and the epistemological stance is social constructionism (Fineman, 2003). This is line with the dynamic and processual view of change and situated emotion that are subject to individual's interpretations.

\subsection{Data collection}

Data was collected through in depth semi structured interviews from the leader and nineteen followers from a public sector university in Pakistan. Data was collection continued till theoretical saturation was reached. Snowball sampling technique was used to gain access to the followers as some of them were hesitant to be interviewed 
due to the personal nature of the topic (Creswell, 2003). However, respondents were reassured of confidentiality and anonymity that prompted them to participate in the study. On the contrary, the leader showed keen interest in this research project.

During the interview process, the respondents were asked to reflect backward and forward in relation to the change process and the related emotions. This was because we were mainly interested in the conversation that was more specific to the emotional experiences about the change brought by the leader. We wanted to prevent the respondents from going astray. Respondents were asked about their emotional experiences during the implementation of new changes. Some of the main questions asked form the followers were: what are the key changes brought by the leader? What does this change mean to you? How do you feel about it? What could have been done differently? The main questions asked from the leader were: what are the key changes you have introduced? Why were they important to you? What were the main issues faced in the implementation process? How do you feel about it? and so forth. Probing questions were asked wherever required to gain deeper insights. The interviews lasted between 15 to 60 minutes from various respondents that were recorded with permission. Later, the interviews were transcribed with the assistance of the software Exam Scribe. The names of the participants and the organization is kept anonymous to protect their confidentiality.

\subsection{Data analysis}

Data was analyzed through thematic analysis to bring out the emergent patterns from the data (Richards, 2005). The thematic analysis helped to understand emotional experiences in situated context that were shared or not shared among the participants. In the first instance, difference of opinion exists on how emotions will be identified. In contrast to positivist who try to measure emotions in human physiologist, social constructionist locates emotions both in text and embodiment. Hence, "Emotions are expressed in single words or sentences, metaphors, figurative language and prosody that do not explicitly reference emotions but provide information concerning emotional impression and attitude through their semantic content" (Kleres, 2010: 13). Additionally, "prosody which is the rhythm, stress and intonation of speech and voice characteristics such as emphasis and expressively stretched words (e.g. ooooh) also reflects emotions" (ibid: 14). Thus, the first author took notes during the interviews that helped to interpret emotions in the text. This was then shared with other authors and was discussed to ensure reliability and validity in the interpretation of the date. Also, the entire coding process was shared with all the coauthors.

Data analysis of the data was done through five phases of thematic analysis that include getting familiarization with the data, generating initial codes, followed by 
higher order codes, themes and ultimately thematic categories (Howitt, 2010). The themes and thematic categories are shown in table 1 .

Table 1: Building Thematic Categories

\begin{tabular}{|c|c|}
\hline Thematic categories & Themes \\
\hline \multirow[t]{4}{*}{ Exclusion from the change process } & $\begin{array}{c}\text { Feeling lack of involvement in the change } \\
\text { process. }\end{array}$ \\
\hline & $\begin{array}{l}\text { Rejecting employee's consultations and sugges- } \\
\text { tions. }\end{array}$ \\
\hline & Lack of communication about change. \\
\hline & Ambiguity in taking responsibilities \\
\hline \multirow[t]{3}{*}{ Bringing change in system and processes } & Building relationships with community. \\
\hline & $\begin{array}{l}\text { Increased efficiency through technological } \\
\text { advancements. }\end{array}$ \\
\hline & Motivating employees for new ideas. \\
\hline \multirow[t]{4}{*}{ Declining change and its repercussions } & Perception about change and government jobs. \\
\hline & Reluctance to change. \\
\hline & Difficulty in managing change. \\
\hline & $\begin{array}{c}\text { Consequences of not being able to cope with } \\
\text { change. }\end{array}$ \\
\hline
\end{tabular}

Data analysis began with first reading the data several times on different occasions to extract out the emotional experiences related to change. The emotions were identified both in language and embodiment in specific context (Kleres, 2011). Then, these passages were (re)read again to create a set of basic codes which were our initial codes (Saldaña, 2009). These were then shared with all the co-authors who then reached to a consensus on the coding process to obtain rigor and to improve research validity and reliability. Similar codes were categorized to form themes that reflects the shared patterns. Lastly, themes were merged to form our thematic categories that are discussed in the next section.

\section{Findings}

Findings show that a wide range of emotional experiences emerged from the data, both positive and negative, regarding various aspects of change specifically during change implementation. These emotions were manifested when followers felt excluded from the change process; when followers were encouraged to accept and implement change; and when they feared facing the repercussions of not accepting the changes brought by the leader. 


\subsection{Exclusion from the change process}

Followers believed that they had not received enough information about the change and that they were excluded from meetings in which the change was decided. They also stated that they avoided taking new responsibilities and were also ambiguous about it due to lack of clarity. Further, they felt that the suggestions given by followers were taken as personal by the leader. These concerns are reflected below:

"Our suggestions are often not listened to because our leader thinks that we are correcting him, but this is not the case. We tried to have improvements in the system that we feel are the best for this organization. We often try to avoid taking responsibilities as we are not involved in the meetings that results in change; and often we are not clear about our responsibilities after the change. So, we feel hesitant" (Follower 2)

Others believed that the leader encourages new ideas and has empowered them to bring changes within their own domain, which made them happy. This is reflected from the following quote:

"The new leader encourages us to bring new ideas in the organization. He has given us the opportunity to bring changes to increase the image and reputation of this organization. This is a very positive thing and I am very happy about it." (Follower 13).

Though the followers had different opinions about being involved and empowered in introducing and implementing change, the leader was confident in his opinion that he encouraged everyone to participate in the change process. Followers were often asked about their suggestions for solution to problems for the betterment of the organization. He believed that the leader should listen to his followers for making the best decision.

"I believe that any leader who ever comes should have the courage to listen to other people to have the best solution, and this approach helps to make employees comfortable with your approach" (Leader).

Apart from the followers' support, the leader also needed support from the top management team that required him to build consensus with them. The leader indicated the complications involved in getting support from the top management team; however, he took it as a part of life.

"Well, top management is pretty much supportive in a way that we go for consensus and they try to understand what I am saying and talking about. I have no issues with them. However, sometimes things get complicated but it is a part of life" (Leader).

This shows that there was a difference of view of the leader and the followers 
since the followers believed that they were excluded from the change process whereas the leader believed that the followers were involved in the decision making process to bring a change.

\subsection{Encouraging followers to accept and implement change}

According to the followers, it is usually the top down change in the bureaucratic organization which lead to the changing of overall system and processes. Respondents believed that the purpose of their organization is to serve its community by providing education. This gave them satisfaction and a feeling of being relaxed.

"We have to build strong relationships with the community, which was a hurdle in the past and now day by day we are getting closer to the community. This is very much relaxing and motivating as it enables the employee of the community to serve their actual purpose" (Follower 1)

This was achieved by arranging seminars and orientation programs in the university by the leader.

"Now to build strong connections with the community, I am arranging seminars and orientation programs, so they could easily build connections with us" (Leader)

One of the major changes in the system and processes was the technological advancement as the organization was shifting from manual to computerized system. The purpose was to increase efficiency and minimize paperwork. This specific change gave them a sense of pride and achievement that their organization is performing well as shown in the following quote:

"It is good to have new technological processes in the organization as it brings pride. We can now say that my institution is doing well and up to the mark and it also has a bring bright future" (Follower 6).

Similar to the followers, the leader also felt that computerization was the major change that he had brought in this organization. Therefore, the leader tried his best for a technological shift in the organization by introducing the e-filing system in the organization.

"One big change that I have introduced is computerization that plays a very important role in the success of an organization, and there has been some resistance". (Leader).

The leader had streamlined the ORIC (Office of Research, Innovation and Commercialization) and had introduced prize competitions among various departments for the generation of best ideas and research projects to the university. He perceived that the employees would be happy about it. 
"I am encouraging my staff to bring new ideas that should be fruitful for the university. I have made a proper plan with the ORIC. We are working on it. In that plan, we will be giving prizes to those department who will bring best ideas and research projects to the university, and I feel that staff and employees are really happy about it" (Leader).

This feeling of happiness was confirmed by several followers who felt enthusiastic to generate new ideas and they had started to struggle to bring research projects to the university. The leader had a similar opinion of employees' behavior and actions.

\subsection{Unwillingness to accept change and the fear of its repercussions}

Some of the followers believed that the changes introduced by the leaders were problematic for them since they were not trained for it. Several followers were not equipped with using computers or working with different software. They even thought that the top management team and their immediate bosses were unaware of its usage. This meant that they had to do their tasks as well, which was a burden for them.

"So far, I have observed that this leadership has brought changes that many of us are not trained for, such as, online system. Now everything will be done through online channel and we have to reduce the filling system and most of our top management and our bosses are illiterate in it. So, they put burden on us as we have to do everything for them" (Follower 10)

They were unhappy with their immediate bosses who they found less tolerant to their suggestions. Also, the lack of appreciation despite of doing their part of the work demotivated them during the change implementation process.

"I am worried to say that our opinions and suggestions are not tolerated, and we are not appreciated for our good work by our immediate bosses. Hence, we get demotivated during this process" (Follower 18).

On the other hand, the leader tried to arrange training programs for them to learn the new technology for a smooth transition from manual work to computerization. He was supportive and open to the followers' suggestions as he thought they might have better solutions to the problems.

"For non-academic employees, I am planning to arrange certain trainings. Few of them have started. I encourage them to learn and if they need any help through training, I will provide that as well...I listen to others opinion as well by thinking they might have better solution than I do" (Leader)

Also, the leader believed in creating a stress-free environment where everyone could relax. Some of the followers thought that the change process had affected their personal lives that the leader denied. He took it as an excuse from the followers to 
deny change. He believed in creating a stress-free environment so that everyone could perform better.

"During my tenure, I have never given any letter to any teacher or any other employee. I believe there is no need of taking action because it will not work. I believe that relax environment is very much needed to make people to work hard. This is achieved through creating a relaxed and a happy environment." (Leader)

This shows the difference of perspectives of the leader and the follower as the followers tried to give excuses in accepting change brought by the leader.

\section{Discussion and Conclusion}

This study unfolds the emotional experiences of the leader and the follower in a situated relational context that emerged during the change processes, particularly during the implementation phase, triggered by the leader in a public-sector university. A range of positive and negative emotions emerged, such as, happiness, challenge, uneasiness, uncertainty, joy, burden, and frustration asserting that both positive and negative emotions can co-exist, and are subject to an individual's interpretation (Klarner et al., 2011). Followers' emotions were manifested when they felt excluded from the change process; when leader encouraged the acceptance and implementation of the change process, and when they feared repercussions over their unwillingness to accept change. Hence, the emergence of various emotions depends on the way followers gave different meanings to a single change that revealed the microprocesses and various interpretations involved in the change process. On the other hand, the leader had his own interpretations and at times had different situated emotions as compared to the followers. Emotions irrespective of whether they were negative or positive emerged as a 'resource' that helped to understand various situations (Fineman, 2003; Giæver, 2009; Jarrett, 2004; Manzoor et al., 2018). The understanding of various situations is important as it helps the leader and the management to take constructive steps that positively modify followers' behavior and actions. Hence, we assert that instead of suppressing emotions during change, the change managers should have 'emotional ears' to understand the deeper meaning of individuals behavior during the change process (Jarrett, 2004; Piderit, 2000).

This study has important theoretical contributions. Firstly, it shows both the leader and followers situated emotions in a specific context of change through a social constructionist lens. In this way, it simultaneously interprets both leader and the follower emotions and reveal that their interpretations may vary as they experience different emotions over the same issue or situation. Secondly, the emergence of positive emotions, such as, happiness, joy, sense of pride and achievement is a contribution in 
the change and change management literature as less is known about them (Kiefer, 2002; Kiefer, 2005; Helpap \& Bekmeier-Feuerhahn, 2016).

Future research should be conducted to understand dynamic emotions as change progresses and evolves over time. Same set of questions can be asked after some time to see how situations and emotions changed over time. This is supported by several researchers who argue that researchers mostly focus on a single change, which actually neglects the fact that organizations have to change on repeated manners (Vermeulen, Puranam, \& Gulati, 2010; Klarner et al., 2011). Secondly, it will be useful to explore and understand the emotion coping strategies of employees during the change process (Klarner et al., 2011). Thirdly, the cultural context of the organization in terms of shaping the experience and expression of emotions could be studied in future.

This study has practical implications too. It can help the organizational leaders to understand the issues that are of emotional significance so that better policies could be designed while implementing change to ensure successful change management. In line with the current literature, leaders need to understand the factors that cause resistance. They should try to explore the actual problem and how these organizational changes are going to impact the employees as it will create trust and appreciation of the leader (Carr, 2001; Pritchard, 2014). It reflects the leader's support to arrange the training programs for the followers and the support that he think he provided for the successful implementation of the change implementation process. Also, engagement of employees in the change process is crucial for follower's commitment and ownership in the change process and its implementation (Carr, 2001; Leech \& Fulton, 2008; Lim \& Daft, 2004; Pihlak \& Alas, 2012; Trignano, 2010). Hence, this study can benefit other leaders to understand the dynamics of the change process while introducing and implementing change in an organization.

\section{References}

Anderson, P. A. \& Guerrero, L. K. (1998). Principles of communication and emotion in social interaction. In P. A. Anderson \& L. K. Guerrero (Eds.), Handbook of communication and emotion: Research, theory, applications, and contexts (pp. 49-96). San Diego, CA: Academic Press.

Agote, L., Aramburu, N., \& Lines, R. (2016). Authentic leadership perception, trust in the leader, and followers' emotions in organizational change processes. The Journal of Applied Behavioral Science, 52(1), 35-63.

Armenakis, A. A., \& Bedeian, A. G. (1999). Organizational change: a review of theory and research in the 1990s. Journal of Management, 25(3), 293-315.

Avey, J. B., Wernsing, T. S., \& Luthans, F. (2008). Can positive employees help positive organizational change? impact of psychological capital and emotions on relevant attitudes and behaviors. The 
Journal of Applied Behavioral Science, 44(1), 48-70.

Carr, A. (2001). Understanding emotion and emotionality in a process of change. Journal of Organizational Change Management, 14(5), 421-436.

Creswell, J. W. (2003). Research design: Qualitative, quantitative, and mixed methods approaches. London: Sage Publications Ltd.

Dasborough, M., Lamb, P., \& Suseno, Y. (2015). Understanding emotions in higher education change management. Journal of Organizational Change Management, 28(4), 579-590.

Elfenbein, H. A. (2007). Emotion in organizations: A review and theoretical integration. Academy of Management Annals, 1, 371-457.

Eriksson, C. B. (2004). The effects of change programs on employees' emotions. Personnel Review, 33(1), 110-126. Retrieved from https://doi.org/10.1108/00483480410510642

Fineman, S. (2003). Understanding emotion at work. London: Sage Publications Ltd.

Fineman, S. (2016). Organizing and emotion: Towards a social construction. In J. Hassard \& M. Parker (Eds.), Routledge revivals: Towards a new theory of organizations (1994) (pp. 97-108). New York, NY: Routledge.

Giæver, F. (2009). Looking forwards and back: Exploring anticipative versus retrospective emotional change-experiences. Journal of Change Management, 9(4), 419-434.

Giæver, F., \& Hellesø, R. (2010). Negative experiences of organizational change from an emotions perspective. Nordic Psychology, 62(1), 37-52.

Glasø, L., Ekerholt, K., Barman, S., \& and Einarsen, S. (2006). The instrumentality of emotion in leader-subordinate relationships. International Journal of Work Organisation and Emotion, 1(3), 255-276.

Groves, K. S. (2006). Leader emotional expressivity, visionary leadership, and organizational change. Leadership E⿱ Organization Development Journal, 27(7), 566-583.

Härtel, C. E. J., \& Zerbe, W. J. (2002). Myths about emotions during change. In N. M. Ashkanasy, W. J. Zerbe \& C. E. J. Härtel (Eds.), Managing emotions at workplace (pp. 70-76). New York, NY: M. E. Sharpe.

Helpap, S., \& Bekmeier-Feuerhahn, S. (2016). Employees' emotions in change: Advancing the sensemaking approach. Journal of Organizational Change Management, 29(6), 903-916.

Howitt, D. (2010). Introduction to qualitative methods in psychology. Harlow: Pearson Education Ltd.

Huy, Q. N. (2002). Emotional balancing of organizational continuity and radical change: The contribution of middle managers. Administrative Science Quarterly, 47(1), 31-69.

Jarrett, M. (2004). Tuning into the emotional drama of change: Extending the consultant's bandwidth. Journal of Change Management, 4(3), 247-258. 
Kavanagh, M. H., \& Ashkanasy, N. M. (2006). The impact of leadership and change management strategy on organizational culture and individual acceptance of change during a merger. British Journal of Management, 17(S1), S81-S103.

Kiefer, T. (2002). Understanding the emotional experience of organizational change: Evidence from a merger. Advances in Developing Human Resources, 4(1), 39-61.

Kiefer, T. (2005). Feeling bad: Antecedents and consequences of negative emotions in ongoing change. Journal of Organizational Behavior, 26(8), 875-897.

Klarner, P., By, R. T., \& Diefenbach, T. (2011). Employee emotions during organizational change-Towards a new research agenda. Scandinavian Journal of Management, 27(3), 332-340.

Kleres, J. (2011). Emotions and narrative analysis: A methodological approach. Journal for the Theory of Social Behaviour, 41(2), 182-202.

Leech, D., \& Fulton, C. (2008). Faculty perceptions of shared decision making and the principal's leadership behaviors in secondary schools in a large urban district. Education, 128(4), 630-644.

Lim, C., \& Daft, R. (2004). The leadership experience in Asia. Singapore: Thomson Learning.

Liu, Y., \& Perrewè, P. L. (2005). Another look at the role of emotion in the organizational change: A process model. Human Resource Management Review, 15(4), 263-280.

Manzoor, H., Johnson, N., \& Rashid, M. Ur. (2018). Emotions during executive succession in a public board. Journal of Organizational Change Management, 31(3), 766-776.

Maitlis, S., \& Sonensheim, S. (2010). Sensemaking in crisis and change: Inspiration and insights from Weick. Journal of Management Studies, 47(3), 551-580.

Parveen, A., Rashid, K., Iqbal, M. Z., \& Khan, S. (2011). System and reforms of higher education in Pakistan. International Journal of Business and Social Science, 2(20), 260-267.

Piderit, S. K. (2000). Rethinking resistance and recognizing ambivalence: A multidimensional view of attitudes toward an organizational change. Academy of Management Review, 25(4), 783-794.

Pihlak, U., \& Alas, R. (2012). Leadership style and employee involvement during organizational change. Journal of Management $\mathcal{E}$ Change, 29(1), 46-66.

Pritchard, K. (2014). Tackling the challenges of leading through change. Strategic HR Review, 13(1), 16-19.

Richards, L. (2005). Handling qualitative data: A practical guide. London: Sage Publications.

Saldaña, J. (2009). The coding manual for qualitative researchers. London: Sage Publications.

Spoor, J. R., \& Kelly, J. R. (2004). The evolutionary significance of affect in groups: Communication and group bonding. Group Processes and Intergroup Relations, 7(4), 398-412.

Staw, B. M., \& Barsade, S. G. (1993). Affect and managerial performance: A test of the sadder-but-wiser 
vs. happier-and-smarter hypotheses. Administrative Science Quarterly, 38(2), 304-331.

Smollan, R. K. (2011). The multi-dimensional nature of resistance to change. Journal of Management and Organization, 17(6), 828-849.

Smollan, K. R. (2014). Control and the emotional rollercoaster of organizational change. International Journal of Organizational Analysis, 22(3), 399-419.

Tsoukas, H. (1998). Forms of knowledge and forms of life. In R. Chia (Ed.), In the realm of organization (pp. 43-66). New York, NY: Routledge.

Saunders, M. N. K., \& Thornhill, A. (2003). Organisational justice, trust and the management of change: An exploration. Personnel Review, 32(3), 360-375.

Smollan, R. K., \& Parry, K. (2011). Follower perceptions of the emotional intelligence of change leaders: A qualitative study. Leadership, 7(4), 435-462.

Smollan, R. K., \& Sayers, J. G. (2009). Organizational culture, change and emotions: A qualitative study. Journal of Change Management, 9(4), 435-457.

Thiel, C. E., Connelly, S. \& Griffith, J. A. (2012). Leadership and emotion management for complex tasks: Different emotions, different strategies. The Leadership Quarterly, 23(3): 517-533.

Tiedens, L. Z., \& Linton, S. (2001). Judgment under emotional certainty and uncertainty: The effects of specific emotions on information processing. Journal of Personality and Social Psychology, 81(6), 973-988.

Trignano, L. (2010). The change challenge. Financial Executive, 26(9), 56-59.

Tsoukas, H., \& Chia, R. (2002). On organizational becoming: Rethinking organizational change. Organization Science, 13(5), 567-582.

Vermeulen, F., Puranam, P., \& Gulati, R. (2010). Change for change's sake. Harvard Business Review, 88(6), 71-76.

Vince, R. (2006). Being taken over: Managers' emotions and rationalizations during a company takeover. Journal of Management Studies, 43(2), 343-365.

Vince, R., \& Broussine, M. (1996). Paradox, defense and attachment: Accessing and working with emotions and relations underlying organizational change. Organization Studies, 17(1), 1-21.

Weick, K. E., \& Quinn, R. E. (1999). Organizational change and development. Annual Review of Sociology, 50, 361-386. 
